\title{
Examining formation and dissolution of Fe-rich incipient weathering products using field, laboratory, and reactive transport modeling approaches
}

\author{
E.M. HAUSRATH ${ }^{1, *}$, A.D. FELdMAN ${ }^{1}$, N. LUU ${ }^{1}$, T.S.
}

PERETYAZHKO ${ }^{2}$, A.W. Provow ${ }^{1}$, S.J. RALSTON ${ }^{2}$, E. B. RAMPE $^{3}$, AND A. SANCHEZ ${ }^{1}$

${ }^{1}$ Dept. of Geoscience, UNLV, Las Vegas, NV

(*correspondence: Elisabeth.Hausrath@unlv.edu)

${ }^{2}$ Jacobs, NASA Johnson Space Center, Houston, TX

${ }^{3}$ NASA Johnson Space Center, Houston, TX

Abundant evidence exists for past liquid water on Mars, but many questions remain about ancient aqueous environments. Recent X-Ray Diffraction and Evolved Gas Analysis measurements on Mars have indicated the presence of volatile-containing Fe-rich X-ray amorphous materials [1, $2]$, at least some of which are likely weathering products. However, what these weathering products may indicate about past aqueous conditions on Mars is still unknown.

Therefore, we are examining the formation and dissolution of poorly crystalline $\mathrm{Fe}$-rich weathering products using a combination of field work, laboratory experiments, and reactive transport modeling. We are examining weathering products formed on Fe-rich parent material under a range of climates, ages, and extents of serpentinization, including arid Pickhandle Gulch, NV, subarctic Tablelands, Newfoundland, and the Mediterranean Klamath Mountains, $\mathrm{CA}$. We are examining the dissolution rates of poorly crystalline material, and the secondary products that form from the alteration of these components, and modeling the dissolution and precipitation of secondary materials using CrunchFlow[3]. The field studies reveal the formation of Xray amorphous materials that persist in the Tablelands, Newfoundland, but are converted to smectites in the Klamath Mountains, CA. Laboratory experiments demonstrate the rapid dissolution of iron-rich poorly crystalline materials in aqueous solutions and incipient formation of phyllosilicatelike phases. Reactive transport modeling confirms distinct signatures of alteration [3]. More work is needed to understand the implications of these poorly crystalline components for past aqueous conditions on Mars.

References: [1].Sutter, B., et al., JGR 122(12): p. $2574-$ 2609. [2]. Rampe, E.B., et al. EPSL, 2017. 471: p. 172185.[3] Hausrath, E.M., et al., EPSL, 2018. 491: p. 1-10. 